\title{
MORPHOLOGY OF SUPRASCAPULAR NOTCH AND ITS CLINICAL
} SIGNIFICANCE

\section{Sachin Patil ${ }^{1}$, Sandeep Saluja ${ }^{* 2}$, Neelam Vasudeva ${ }^{3}$.}

${ }^{1}$ Assistant professor, Department of Anatomy, ANIIMS, Port Blair, A\&N Islands, India.

*2 Assistant professor, Department of Anatomy, G S Medical College and Hospital, Pilkhuwa, Hapur,(U.P.), India.

${ }^{3}$ Director professor, Department of Anatomy, MAMC, New Delhi, India.

\section{ABSTRACT}

Introduction: The suprascapular notch is present on the superior border of the scapula, just medial to the coracoid process. The suprascapular ligament bridges the edges of notch, which sometimes get ossified and convert suprascapular notch into foramen.A narrow notch or excess ossified ligament may have a greater chance of a nerve impingement in the suprascapular foramen.

Materials and methods: This study was conducted on the bones that were obtained from the bone bank of Department of Anatomy. A total of 118 (57 right, 61 left) human scapulae derived from adult (35 male and 17 female) skeletons were evaluated for the shape of suprascapular notch ,presence of any ossification of the suprascapular ligament and classified according to Rengachary et al into I -VI types.

Results: On analysis of morphological variations of suprascapular notch, we found following types of scapulae: Type I-22.42\%, Type II -12.98\%, Type III -53.98\%, Type IV -0\%, Type V- 7.08\%, Type VI-3.54\%.. Out of all specimens, in three specimen suprascapular ligaments (3.54 \%) were found to be completely ossified

Conclusion: The knowledge of morphometric variations of suprascapular notch and ossification of suprascapular ligament is very important for clinicians. This knowledge is very important in sports medicine as well as for orthopaedic surgeons in management of cases of shoulder pain.

KEY WORDS: Suprascapular notch, Suprascapular nerve, Suprascapular ligament, Suprascapular foramen.

Address for Correspondence: Dr Sandeep Saluja, Assistant professor, Department of Anatomy, G S Medical College and Hospital, Pilkhuwa, Hapur,(U.P.),India-245304

E-Mail: sandeep.saluja1980@gmail.com

Access this Article online

Quick Response code

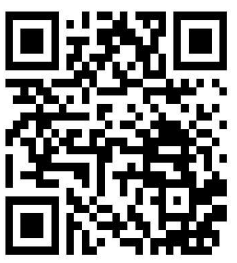

DOI: $10.16965 /$ ijar.2019.132

Journal Information

International Journal of Anatomy and Research

ICV for 2016 ISSN (E) 2321-4287 | ISSN (P) 2321-8967

90.30

https://www.ijmhr.org/ijar.htm

DOI-Prefix: https://dx.doi.org/10.16965/ijar

Article Information

Received: 31 Jan 2019

Peer Review: 02 Feb 2019

Revised: None
Accepted: 07 Mar 2019

Published (O): 05 Apr 2019

Published (P): 05 Apr 2019

\section{INTRODUCTION}

The suprascapular nerve is the branch from the upper trunk of the brachial plexus at Erb point. It receives contributions from $\mathrm{C} 5$ and $\mathrm{C} 6$ nerve roots [1]. The nerve travels through the suprascapular notch to enter the supraspinatus fossa. The suprascapular nerve passes below the transverse scapular or suprascapular ligament whereas the suprascapular vein and artery travels above the ligament [2]. The suprascapular nerve supplies the supraspinatus and infraspinatus muscles, the coracohumeral and coracoacromial ligaments, subacromial bursa, and the acromioclavicular joint [3].

The variations of the morphology of the notch have been analysed in which different correlation has been found between notch type and 
injury frequency. Ossification of the suprascapular ligament results in conversion of suprascapular notch into foramen (foramen scapulae) through which the suprascapular nerve passes [4]. Compression in the narrowed foramen result in suprascapular nerve neuropathy. Compression of the suprascapular nerve may be due to multiple pathologies, including tumors, congenital abnormalities of the scapula, fractures of the scapula, ganglion cysts and an ossified suprascapular ligament [5].

The suprascapular nerve entrapment may be due to traumatic or non-traumatic. The suprascapular nerve is commonly compressed at the level of the suprascapular notch and the scapular spine. The suprascapular nerve compression is commonly associated with sports activities like gymnastics, tennis, weightlifting, boxing, and baseball [6].

During arthroscopic shoulder operations, suprascapular notch is an important landmark for location of the suprascapular nerve.

This study was conducted to study morphological variations of suprascapular notch in dry scapulae and to report the incidence of ossified superior transverse scapular ligament and compare it with other ethnic populations.

\section{MATERIALS AND METHODS}

This descriptive study was conducted on the bones that were obtained from the bone bank of Department of Anatomy, Maulana Azad Medical College, New Delhi, India. The bones showing morphological anomaly or broken ends or shaft were excluded from study. The scapulae were cleaned, dried and studied in proper daylight .A total of 118 (57 right, 61 left) human scapulae derived from adult ( 35 male and 17 female) skeletons were evaluated for the shape of suprascapular notch , presence of any ossification of the suprascapular ligament and classified according to Rengachary et al into $\mathrm{I}-\mathrm{VI}$ types. When an ossified suprascapular ligament was identified, the diameter of the resultant foramen was measured with microcaliper. Statistical analysis was performed between sides and sexes using Statistical 16.0 for Windows with significance set at $P<0.05$. For normalization of data, student's $t$ statistics were applied.

\section{OBSERVATIONS AND RESULTS}

In the present study out of 118 scapulae, 40 (10\%) scapulae were found to have completely ossified superior transverse scapular ligaments. Representative photographs of various notch types in our study are shown in [Fig-1]. On analysis of morphological variations of suprascapular notch, we found: Type I-22.42\%, Type II $-12.98 \%$, Type III $-53.98 \%$, Type IV -0 \%, Type V$7.08 \%$, Type VI-3.54\%. [Table 2]. Out of all specimens, in three specimen suprascapular ligaments ( $3.54 \%$ ) were found to be completely ossified [Figure 2]. These were identified in 1 female (left scapula) and 2 male (right scapulae) specimens. The diameters of the resultant foramina ranged from 1.7 to $4.5 \mathrm{~mm}$ (mean 2.6 $\mathrm{mm}$ ).In our study no type VI the scapula was found.

Fig. 1: The photographs of the various notch types from our study, as per Rengachary's classification.

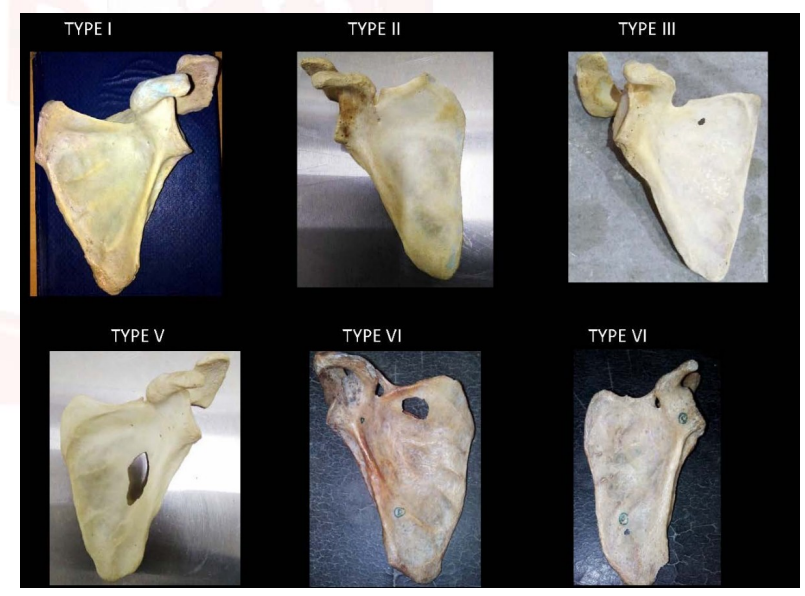

Table 1: The percentage of various types of suprascapular notch as per Rengachary's classification in our study.

\begin{tabular}{|c|c|c|}
\hline $\begin{array}{c}\text { Type of suprascapular } \\
\text { notch }\end{array}$ & $\begin{array}{c}\text { Number of } \\
\text { Scapulae }\end{array}$ & Percentage \\
\hline I & 19 & $22.42 \%$ \\
\hline II & 11 & $12.98 \%$ \\
\hline III & 46 & $53.98 \%$ \\
\hline IV & 0 & $0 \%$ \\
\hline V & 6 & $7.08 \%$ \\
\hline VI & 3 & $3.54 \%$ \\
\hline
\end{tabular}

\section{DISCUSSION}

The most common relation at the suprascapular notch is that the artery travels superior to the suprascapular ligament while the nerve 
travels below it [7]. Common reasons for suprascapular nerve entrapment include ossification of suprascapular ligament direct trauma, fracture of the scapula, ganglion cysts, lipomas, tumours, occupational overuse, and stretch injuries. This is due to narrowing of anatomical space of the suprascapular notch [8].

Different authors has classified suprascapular notch on basis of morphological appearance as $\mathrm{U}$ and $\mathrm{V}$. J on gross examination. Some authors has distinguished $V$ notch on the basis of vertical and transverse diameter measurements [9-10].

Six different types of suprascapular notch anatomy were originally defined by Rengachary et al. The type I notch lacks a discrete notch. Type II is a wide V-shaped notch, whereas type III is a wide U-shaped notch. Type IV is a narrower V-shaped notch with partial ossification of suprascapular ligament and type $V$ is a U-shaped notch with partial ossification of the suprascapular ligament. The type VI notch is defined as a completely ossified suprascapular ligament which converts suprascapular notch into foramen [12,13].

Compared to other painful conditions on the shoulder, suprascapular nerve entrapment is a rare syndrome causing severe shoulder pain and reduced mobility. It is easily cured by arthroscopic approach by addressing the suprascapular nerve entrapment at suprascapular notch [14-16].

Incidence of completely ossified suprascapular ligament in Indian population in different studies is shown in table 2 .

Table 2: Incidence of completely ossified suprascapular ligament in Indian population in different studies.

\begin{tabular}{|c|c|c|c|}
\hline Sr no & Author & Population & $\begin{array}{c}\text { Percentage of ossified } \\
\text { suprascapular ligament }\end{array}$ \\
\hline 1 & Kajava & Finnish (133) & $1.50 \%$ \\
\hline 2 & Sinkeet et al. & Kenyan (138) & $4 \%$ \\
\hline 3 & Wang HJ et al. & Chinese (295) & $1.36 \%$ \\
\hline 4 & DJ Gray & Brazilian (221) & $30.76 \%$ \\
\hline 5 & Rengachary et al. & American (211) & $4 \%$ \\
\hline 6 & Paolo Albino et al. & Italian (500) & $3.60 \%$ \\
\hline 7 & Usha Kannan et al & Indian (400) & $10 \%$ \\
\hline 8 & Present study & Indian(118) & $3.54 \%$ \\
\hline
\end{tabular}

\section{CONCLUSION}

The knowledge of morphometric variations of suprascapular notch and ossification of suprascapular ligament is very important for clinicians.
This knowledge is very important in sports medicine as well as for orthopaedic surgeons in management of cases of shoulder pain. Radiologists can easily diagnosed such cases by using imaging modalities like MRI, CT and Ultrasound .Further histopathological studies on suprascapular nerve are needed to get more information on this matter

\section{Conflicts of Interests: None}

\section{REFERENCES}

[1]. Standring S Ellis H, Healy J, Johnson D, Williams A. 2005 Pectoral girdle, shoulder region and axilla. Gray's Anatomy - The Anatomical Basis of Clinical Practice. 39th ed. New York: Elsevier Churchill Livingstone;; 821-2.

[2]. Harmon D, Hearty C. Diameter of suprascapular nerve in the suprascapular notch. Pain Phys. 2008;11:263-4.

[3]. Rengachary SS, Burr D, Lucas S, Hassanein KM, Mohn MP, Matzke H. Suprascapular entrapment neuropathy: a clinical, anatomical, and comparative. Study Part 2: anatomical study. Neurosurgery. 1979;5(4):447-51.

[4]. Lafosse L, Tomasi A, Corbett S, Baier G, Willems K, Gobezie R. Arthroscopic release of suprascapular nerve entrapment at the suprascapular notch: technique and preliminary results. Arthroscopy. 2007;23:34-42.

[5]. Shishido H, Kikuchi S. Injury to the suprascapular nerve during shoulder joint surgery: an anatomical study. J Shoulder Elbow Surg. 2001;10:372-6.

[6]. Osuagwu FC, Imosemi IO, Shokunbi MT Complete ossification of the superior transverse scapular ligament in a Nigerian male adult. Int J Morphol.2005;23(2):121-2.

[7]. Srijit Das, Rajesh Suri, Vijay Kapur. Ossification of Superior Transverse Scapular Ligament and its Clinical Implications. Sultan Qaboos Univ Med J. 2007 August; 7(2):157-60.

[8]. Paolo Albino, Stefano Carbone, Vittorio Candela, Valerio Arceri, Anna Rita Vestri, Stefano Gumina. Morphometry of the suprascapular notch: correlation with scapular dimensions and clinical relevance. BMC Musculoskelet Disord. 2013;14:172.

[9]. R.Shane Tubbs, Carl Nechtman, Anthony V. D'Antoni, Mohammadali M. Shoja, Martin M. Mortazavi, Marios Loukas, Curtis J. Rozzelle, Robert J. Spinner. Ossification of the suprascapular ligament: A risk factor for suprascapular nerve compression? Int J Shoulder Surg. 2013;7(1):19-22.

[10]. Natsis K, Totlis T, Tsikaras P, Appell HJ, Skandalakis K. Proposal for classification of the suprascapular notch: a study on 423 dried scapulas. Clin Anat. 2007;20:135-9

[11]. Sinkeet SR, Awori KO, Odula PO, Ogeng'o JA, Mwachaka PM. The Suprascapular notch: its 
Morphology and distance from the glenoid cavity in a Kenyan population. Folia Morphol. 2010;69:241-5.

[12]. Wang HJ, Chen C, Wu LP, Pan CQ, Zhang WJ, Li YK. Variable morphology of the suprascapular notch: an investigation and quantitative measurements in Chinese population. Clin Anat. 2011;24(1):47-55.

[13]. Khan MA. Complete ossification of the suprascapular transverse ligament in an male adult. Int J Morphol. 2006;24(2):195-6.

[14]. DJ Gray. Variations in human scapulae. American Journal of Physical Anthropology. 2013;29(1):5772.1942.
[15]. Silva JG, Abidu-Figueiredo M, Fernandes RMP, Aureliano-Rafael F, Sgrot EA, Silva SF, et al. High incidence of ossification of superior transverse scapular ligament in Brazilians and its clinical significance. Int J Morphol. 2007;25(4):855-9.

[16]. Usha Kannan, N.S.Kannan, J.Anbalagan, Sudha Rao. Morphometric Study of Suprascapular Notch in Indian Dry Scapulae with Specific Reference to the Incidence of Completely Ossified Superior Transverse Scapular Ligament. J Clin Diagn Res 2014;8(3):7-10.

How to cite this article:

Sachin Patil, Sandeep Saluja, Neelam Vasudeva. MORPHOLOGY OF SUPRASCAPULAR NOTCH AND ITS CLINICAL SIGNIFICANCE. Int J Anat Res 2019;7(2.1):6420-6423. DOI: 10.16965/ijar.2019.132 